Research article

\title{
Comparative efficacy of two microdoses of a potentized homoeopathic drug, Cadmium Sulphoricum, in reducing genotoxic effects produced by cadmium chloride in mice: a time course study Swapna S Datta, Palash P Mallick and Anisur AR Rahman Khuda-Bukhsh*
}

Address: Cytogenetics Laboratory, Department of Zoology, University of Kalyani, Kalyani-741 235, West Bengal, India

E-mail: Swapna S Datta - arkb@klyuniv.ernet.in; Palash P Mallick - palash_mallick@yahoo.com; Anisur AR Rahman KhudaBukhsh* - arkb@klyuniv.ernet.in

*Corresponding author

Published: 23 November 200I

BMC Complementary and Alternative Medicine 200I, I:9
Received: 2 August 2001

Accepted: 23 November 2001

This article is available from: http://www.biomedcentral.com//472-6882/1/9

(C) 200 I Datta et al; licensee BioMed Central Ltd. Verbatim copying and redistribution of this article are permitted in any medium for any non-commercial purpose, provided this notice is preserved along with the article's original URL. For commercial use, contact info@biomedcentral.com

\begin{abstract}
Background: Cadmium poisoning in the environment has assumed an alarming problem in recent years. Effective antimutagenic agents which can reverse or combat cadmium induced genotoxicity in mice have not yet been reported. Therefore, in the present study, following the homeopathic principle of "like cures like", we tested the efficacy of two potencies of a homeopathic drug, Cadmium Sulphoricum (Cad Sulph), in reducing the genotoxic effects of Cadmium chloride in mice.

Another objective was to determine the relative efficacy of three administrative modes, i.e. pre-, post- and combined pre and post-feeding of the homeopathic drugs. For this, healthy mice, Mus musculus, were intraperitoneally injected with $0.008 \%$ solution of $\mathrm{CdCl}_{2} @ \mathrm{I} \mathrm{ml} / \mathrm{I} 00 \mathrm{gm}$ of body wt (i.e. $0.8 \mathrm{mcg} / \mathrm{gm}$ of bw), and assessed for the genotoxic effects through such studies as chromosome aberrations (CA), micronucleated erythrocytes (MNE), mitotic index (MI) and sperm head anomaly (SHA), keeping suitable succussed alcohol fed (positive) and $\mathrm{CdCl}_{2}$ untreated normal (negative) controls. The $\mathrm{CdCl}_{2}$ treated mice were divided into 3 subgroups, which were orally administered with the drug prior to, after and both prior to and after injection of $\mathrm{CdCl}_{2}$ at specific fixation intervals and their genotoxic effects were analyzed.
\end{abstract}

Results: While the CA, MNE and SHA were reduced in the drug fed series as compared to their respective controls, the $\mathrm{Ml}$ showed an apparent increase. The combined pre- and post-feeding of Cad Sulph showed maximum reduction of the genotoxic effects.

Conclusions: Both Cad Sulph-30 and 200 were able to combat cadmium induced genotoxic effects in mice and that combined pre- and post-feeding mode of administration was found to be most effective in reducing the genotoxic effect of $\mathrm{CdCl}_{2}$ followed by the post-feeding mode.

\section{Background}

Cadmium has been known as a toxic agent in environment which has attracted critical attention for its toxic biological effects [1-10]. The adverse effects of cadmium in biological systems may result in nephrotoxicity, tumorigenicity or carcinogenicity in fowl, mice, rat and human beings [11-22]. Mutagenic effects of cadmium have been extensively studied in microorganisms [23-25] and 
in mammals in vivo[22,26,27]. However, although cadmium poisoning has become an environmental hazard in recent years, attempts to reduce cadmium induced genotoxicity by any possible antimutagenic agent(s) are very few $[28,29]$.

In the present study two microdoses of a potentized homeopathic drug Cadmium Sulphoricum (Cad Sulph) 30 and 200 were fed to mice either before or after the injection of $0.008 \% \mathrm{CdCl}_{2} @ 1 \mathrm{ml} / 100$ gm of body weight of mouse, to examine if either or both of these potencies could positively modulate the cytogenetic effects produced by $\mathrm{CdCl}_{2}$. In fact, the impetus of the study was drawn from our findings that potentized homeopathic drug Arsenicum Album (Ars Alb), derived from succussion and dilution of Arsenic trioxide could successfully and favourably modulate cytotoxic and genotoxic effects of Arsenic trioxide [30-35]. A little deviation has been made in the present experimentation; the homeopathic drug used has actually been derived from a different salt of cadmium through dilution and succussion as per the homeopathic procedure and it was examined if this drug had any ameliorating effect on the genotoxicity produced by the injection of $\mathrm{CdCl}_{2}$, another cadmium salt. Unfortunately, as homeopathic preparations of Cad Chlor-30/ 200 were not available, it was not possible to compare the effects of Cad Chlor and Cad Sulph in combating cadmium poisoning. Another objective of the study was to test the comparative efficacies of the three modes of treatment, i.e., pre-, post- and combined pre- and postfeeding of the homeopathic drug in combating sub-acute cadmium poisoning.

\section{Materials and Methods \\ Materials}

Inbred lines of mice (Mus musculus) cultured and maintained on artificial standard diet and water ad libitum (under the supervision of the animal welfare committee, University of Kalyani) were used as materials for the present study. Generally 3-4 months old healthy adult mice of both sexes weighing between 22-28 gms were selected for the purpose.

\section{Methods}

Treatment of test chemical

Mice were intraperitoneally injected with a single dose of aqueous solution of $\mathrm{CdCl}_{2}(0.008 \%)$ at the rate of $1 \mathrm{ml} /$ 100 gms of body weight (i.e. $0.8 \mathrm{mcg} / \mathrm{g}$ of bw approx) and were sacrificed at 6 different fixation intervals, viz. at 6 $\mathrm{hr}, 12 \mathrm{hr}, 24 \mathrm{hr}, 48 \mathrm{hr}, 72 \mathrm{hr}$ and $96 \mathrm{hr}$.

\section{Administration of potentized homeopathic drug}

$0.06 \mathrm{ml}$ of each of the 30th and 200th potency of the homeopathic drug Cadmium sulphoricum in liquid (90\% ethyl alcohol) prepared by the standard homeopathic procedure of centesimal dilutions and succussions $[32,33]$ by Hapco, 165 Bipin Behari Ganguly Street, Kolkata, was diluted separately with $20 \mathrm{ml}$ of double distilled water to make stock solutions of the homeopathic drug that was orally administered to experimental mice. In India, these two potencies are most commonly used by the homeopathic practitioners and are easily available in the market.

\section{Experimental design and control Drug treated series \\ Drug pre-treated series $\left(T_{1}-T_{2}\right)$}

1 drop of stock solution (0.06 ml) of the homeopathic drug (both 3oth and 20oth potencies in separate series) was orally administered to mice with the aid of a pipette every $4 \mathrm{hr}$ prior to the injection of $\mathrm{CdCl}_{2}$. The respective times of beginning of drug feeding before injection were $6 \mathrm{hr}, 12 \mathrm{hr}, 24 \mathrm{hr}, 48 \mathrm{hr}, 72 \mathrm{hr}$ and $96 \mathrm{hr}$ to the sets of mice destined to be sacrificed at $6 \mathrm{hr}, 12 \mathrm{hr}, 24 \mathrm{hr}, 48 \mathrm{hr}$, $72 \mathrm{hr}$ and $96 \mathrm{hr}$, respectively. As for example, the mice destined to be sacrificed at $24 \mathrm{hr}$ would start receiving

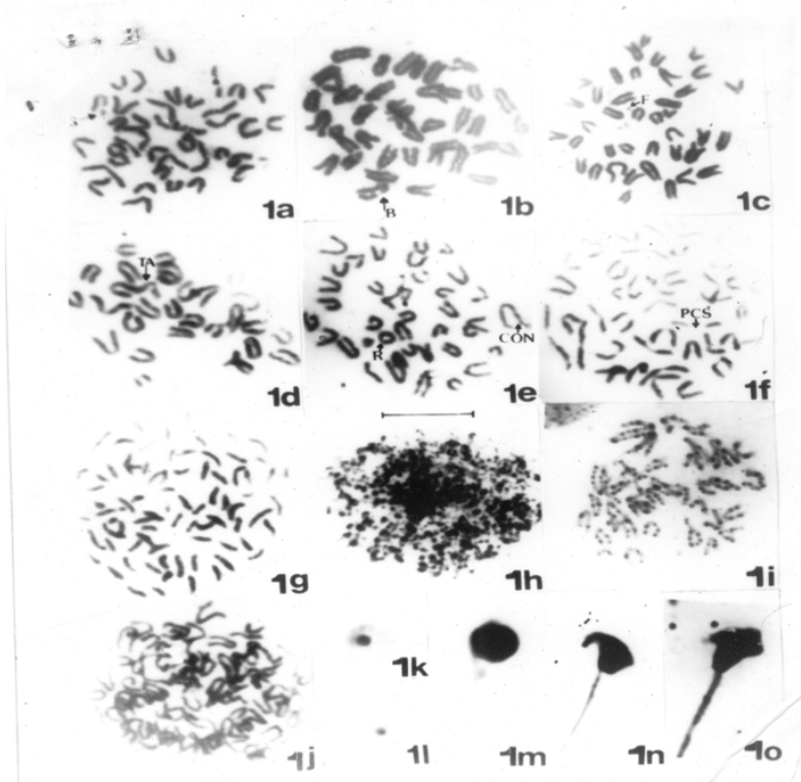

\section{Photomicrograph I}

Photomicrographs. Ia-Ij: Photomicrographs different types of chromosome aberrations showing gap (la), break (Ib), fragment of unknown origin (Ic), terminal association (Id), ring and constriction (le), precocious centromeric separation (If), C-mitotic effect (I g), pulverisation (Ih), erosion (Ii) and polyploidy (Ij). Ik-II: Showing micronucleus in both polychromatic (Ik) and normochromatic (II) erythrocytes. I m-Io: Showing sperm with abnormal head-shapes (I m to Io). 


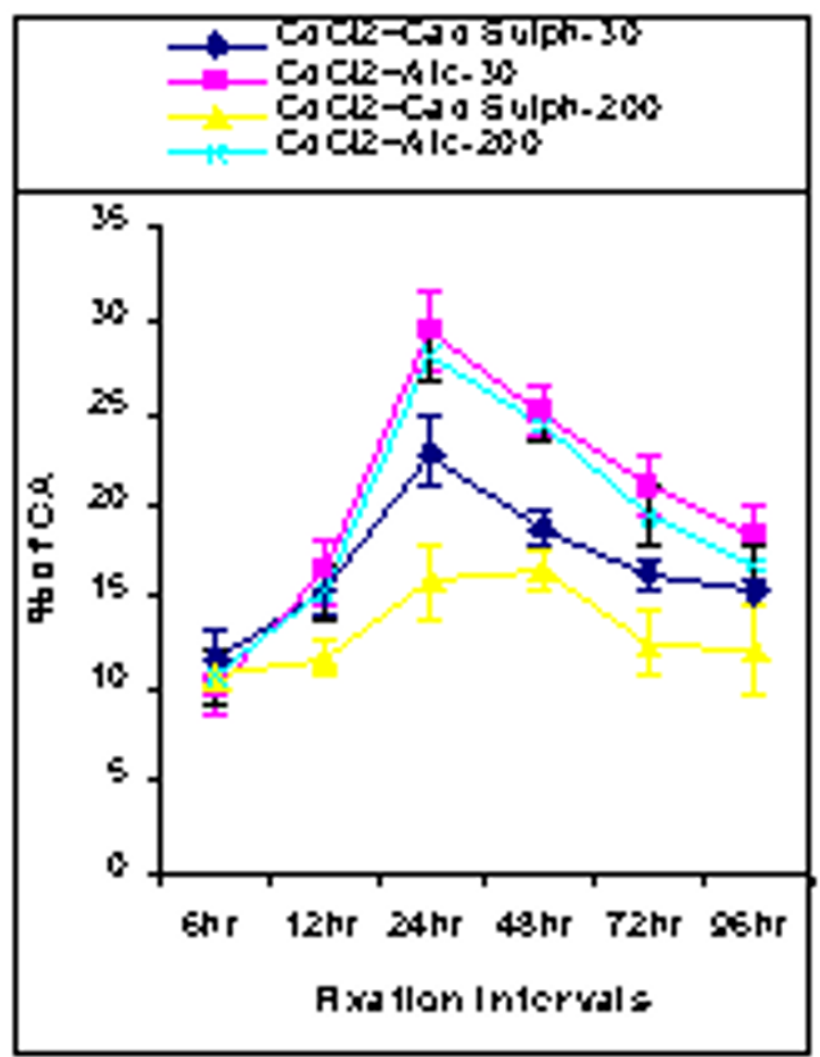

Figure 2

Showing time-dependent frequencies of Cad Sulph-30 prefed and Cad Sulph-200 pre-fed series versus their respective $\mathrm{CdCl}_{2}$ treated alcohol-30 and alcohol-200 control mice. Chromosome aberration (CA)-I; Mitotic index (MI)-2; Micronucleated erythrocytes (MNE)-3 and Sperm head anomaly (SHA)-4.

the homeopathic drug $24 \mathrm{hr}$ before Cadmium chloride injection and those destined to be sacrificed at $48 \mathrm{hr}$ would start receiving the drug $48 \mathrm{hr}$ before injection. In case of pre-fed series, the mice were not fed homeopathic drug after injection. But in the pre- and post-fed combined series, the mice were fed the homeopathic drug both prior to and after the injection. Similarly, in the post-fed series, mice were fed the homeopathic drug only after injection of Cadmium chloride.

Drug post-treated series $\left(T_{3}-T_{4}\right)$

Different sets (consisting of 5 mice each) of adult healthy mice were fed 1 drop (o.06 ml) of the stock solution of drug (either 3oth or 20oth potency) at an interval of 4 hour (during day time only i.e. generally 4 times a day) i.e. the drug was fed twice at an interval of 4 hour to mice sacrificed at $6 \mathrm{hr}$, thrice to mice sacrificed at $12 \mathrm{hr}$ and 6 times to mice sacrificed at $24 \mathrm{hr}$ and so on, starting at 5 minutes after injection.

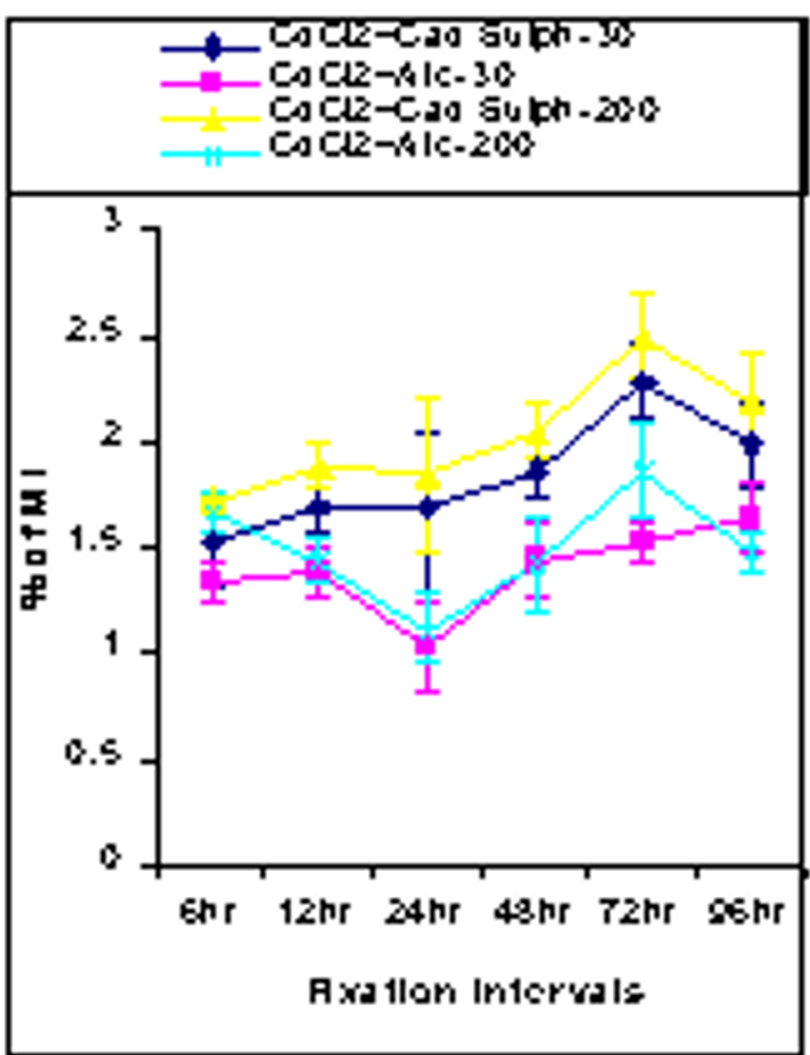

Figure 3

Showing time-dependent frequencies of Cad Sulph-30 prefed and Cad Sulph-200 pre-fed series versus their respective $\mathrm{CdCl}_{2}$ treated alcohol-30 and alcohol-200 control mice. Chromosome aberration (CA)-l; Mitotic index (MI)-2; Micronucleated erythrocytes (MNE)-3 and Sperm head anomaly (SHA)-4.

Combined pre- and post-drug treated series $\left(T_{5}-T_{6}\right)$

In this series different sets of mice (each comprising 5 mice) were fed potentized drug both before and after injection in similar manner as stated above and sacrificed at the 6 different fixation intervals.

Control series $\left(C_{1}-C_{6}\right)$

Since the "vehicle" of the homeopathic drug was $90 \%$ ethyl alcohol, the same was also potentized to form alcohol-30 and alcohol-20o by the homeopathic procedure of dilutions and succussions. 1 drop (0.06 ml) each of alcohol-30 and alcohol-200 was then diluted separately with $20 \mathrm{ml}$ of double distilled water to produce the stock solutions of succussed alcohol-30 and alcohol-200, respectively. 1 drop ( $0.06 \mathrm{ml}$ ) each of the stock solution of alcohol-30 and alcohol-20o was fed to separate sets of mice (also comprising 5 mice in each set) serving as control at all corresponding intervals of the drug treated series. In earlier experiments in this laboratory another 
Table I: Frequency distribution of Chromosome Aberrations (CA) in 500 bone marrow cells examined ( 100 cells from each individuals).

\begin{tabular}{|c|c|c|c|c|c|c|c|c|c|c|c|c|c|c|c|}
\hline \multirow[b]{2}{*}{$\begin{array}{r}\text { Fixation } \\
\text { Intervals } \\
(\mathrm{hr})\end{array}$} & \multirow[b]{2}{*}{$\begin{array}{r}\text { Drug } \\
\text { potency }\end{array}$} & \multirow[b]{2}{*}{ Series } & \multicolumn{2}{|c|}{ Mitotic Index } & \multicolumn{4}{|c|}{ Chromosome Aberration } & \multicolumn{5}{|c|}{ Micronucleated Erythrocyte } & \multicolumn{2}{|c|}{ Sperm Head Anomaly } \\
\hline & & & $\% \pm \mathrm{SE}$ & $\begin{array}{r}\% \text { of } \\
\text { Increased } \\
\mathrm{MI}\end{array}$ & $\begin{array}{r}\% \text { of } \\
\text { Major } \\
\text { CA }\end{array}$ & $\begin{array}{r}\% \text { of } \\
\text { Other } \\
C A\end{array}$ & $\begin{array}{c}\% \text { of Total } \\
C A \pm S E\end{array}$ & $\begin{array}{l}\% \text { of } \\
\text { Prot. }\end{array}$ & $\begin{array}{l}\% \text { of } \\
\mathrm{MN} \text { in } \\
\mathrm{NCE}\end{array}$ & $\begin{array}{r}\% \text { of } \\
M N \text { in } \\
P C E\end{array}$ & $\mathrm{P} / \mathrm{N}$ & $\begin{array}{r}\% \text { of Total } \\
M N \text { in NCE } \\
\& \text { PCE }\end{array}$ & $\begin{array}{l}\% \text { of } \\
\text { Prot. }\end{array}$ & $\begin{array}{r}\% \text { of SHA } \\
\pm \text { SE }\end{array}$ & $\begin{array}{l}\% \text { of } \\
\text { prot. }\end{array}$ \\
\hline \multirow[t]{4}{*}{6} & 30 & $\mathrm{~T}_{1}$ & $1.52 \pm 0.20$ & & 5.4 & 6.2 & $11.6 \pm 1.60$ & & 0.25 & 0.99 & 0.16 & $0.35 \pm 0.04$ & & $1.72 \pm 0.13$ & \\
\hline & & $c_{1}$ & $1.34 \pm 0.17$ & 0.18 & 5.6 & 4.4 & $10 \pm 1.45$ & -1.6 & 0.24 & 0.78 & 0.28 & $0.41 \pm 0.04$ & 0.06 & $1.62 \pm 0.12$ & -0.1 \\
\hline & 200 & & $1.72 \pm 0.02$ & & 4.6 & 6 & $10.6 \pm 1.44$ & & 0.18 & 1.26 & 0.16 & $0.33 \pm 0.06$ & & $1.74 \pm 0.09$ & \\
\hline & & $\mathrm{C}_{2}$ & $1.66 \pm 0.16$ & 0.06 & 4,8 & 5.8 & $10.6 \pm 1.44$ & 0 & 0.26 & 0.76 & 0.30 & $0.37 \pm 0.04$ & 0.04 & $1.56 \pm 0.23$ & -0.18 \\
\hline \multirow[t]{4}{*}{12} & 30 & $\mathrm{~T}_{1}$ & $1.68 \pm 0.11$ & & 6.8 & 8.4 & $15.2 \pm 1.08$ & & 0.23 & 0.71 & 0.03 & $0.33 \pm 0.05$ & & $1.86 \pm 0.13$ & \\
\hline & & $c_{1}$ & $1.38 \pm 0.12$ & 0.3 & 8 & 8.4 & $16.4 \pm 1.75$ & 1.2 & 0.4 & 0.6 & 0.47 & $0.47 \pm 0.04$ & $0.14^{\mathrm{a}}$ & $2.04 \pm 0.20$ & 0.18 \\
\hline & 200 & $\mathrm{~T}_{2}$ & $1.88 \pm 0.11$ & & 4.4 & 7.2 & $11.6 \pm 1.03$ & & 0.25 & 0.77 & 0.30 & $0.37 \pm 0.04$ & & $1.80 \pm 0.15$ & \\
\hline & & $\mathrm{C}_{2}$ & $1.44 \pm 0.19$ & 0.44 & 6.8 & 8.4 & $15.2 \pm 1.55$ & 3.6 & 0.51 & 0.7 & 0.44 & $0.57 \pm 0.06$ & $0.20^{a}$ & $1.96 \pm 0.25$ & 0.16 \\
\hline \multirow[t]{4}{*}{24} & 30 & $\mathrm{~T}_{1}$ & $1.68 \pm 0.38$ & & 9.4 & 13.4 & $22.8 \pm 1.98$ & & 0.46 & 1.22 & 0.38 & $0.67 \pm 0.06$ & & $4.40 \pm 0.30$ & \\
\hline & & $c_{1}$ & $1.04 \pm 0.21$ & $0.64^{a}$ & 15.6 & 13.9 & $29.4 \pm 2.28$ & 6.6 & 0.84 & 1.68 & 0.28 & $1.03 \pm 0.07$ & $0.36 \mathrm{~b}$ & $4.94 \pm 0.29$ & 0.54 \\
\hline & 200 & $T_{2}$ & $1.84 \pm 0.37$ & & 8.2 & 7.6 & $15.8 \pm 1.94$ & & 0.59 & 1.33 & 0.33 & $0.73 \pm 0.05$ & & $4.24 \pm 0.30$ & \\
\hline & & $\mathrm{C}_{2}$ & $1.11 \pm 0.17$ & 0.74 & 14.8 & 13.4 & $28.2 \pm 1.47$ & $12.4^{\mathrm{c}}$ & 0.8 & 1.51 & 0.30 & $0.97 \pm 0.10$ & 0.24 & $4.74 \pm 0.21$ & 0.5 \\
\hline \multirow[t]{4}{*}{48} & 30 & $\mathrm{~T}_{1}$ & $1.86 \pm 0.13$ & & 8.6 & 10.2 & $18,80,96$ & & 0.84 & 1.34 & 0.48 & $1.01 \pm 0.08$ & & $5.24 \pm 0.38$ & \\
\hline & & $c_{1}$ & $1.44 \pm 0.17$ & 0.42 & 12.6 & 12.4 & $25 \pm 1.36$ & $6.2^{b}$ & 1.25 & 1.54 & 0.44 & $1.34 \pm 0.12$ & $0.33^{a}$ & $5.62 \pm 0.31$ & 0.38 \\
\hline & 200 & $\mathrm{~T}_{2}$ & $2.04 \pm 0.13$ & & 8.6 & 7.8 & $16.4 \pm 1.09$ & & 0.87 & 1.5 & 0.51 & $1.07 \pm 0.07$ & & $5.08 \pm 0.38$ & \\
\hline & & $\mathrm{C}_{2}$ & $1.42 \pm 0.23$ & 0.62 & 12.4 & 12 & $24.4 \pm 0.96$ & $8 \mathrm{c}$ & 1.32 & 1.44 & 0.48 & $1.32 \pm 0.11$ & 0.25 & $5.68 \pm 0.44$ & 0.6 \\
\hline \multirow[t]{4}{*}{72} & 30 & $\mathrm{~T}_{1}^{2}$ & $2.28 \pm 0.18$ & & 7.6 & 8.6 & $16.2 \pm 0.89$ & & 0.7 & 1.23 & 0.45 & $0.89 \pm 0.09$ & & $6.18 \pm 0.10$ & \\
\hline & & $c_{1}$ & $1.52 \pm 0.10$ & $0.76^{b}$ & 10 & 11 & $21 \pm 1.45$ & $4.8^{\mathrm{a}}$ & 1.21 & 1.64 & 0.62 & $1.38 \pm 0.04$ & $0.49 c$ & $7.02 \pm 0.20$ & $0.84^{b}$ \\
\hline & 200 & $\mathrm{~T}_{2}$ & $2.5 \pm 0.20$ & & 5.8 & 6.6 & $|2.4 \pm 1.8|$ & & 0.64 & 1.24 & 0.40 & $0.83 \pm 0.13$ & & $6.16 \pm 0.24$ & \\
\hline & & $c_{2}$ & $1.86 \pm 0.23$ & 0.64 & 9.8 & 9.6 & $19.4 \pm 1.48$ & $7 \mathrm{~b}$ & 1.5 & 1.16 & 0.59 & $1.38 \pm 0.13$ & $0.55^{a}$ & $6.98 \pm 0.30$ & 0.82 \\
\hline \multirow[t]{4}{*}{96} & 30 & $T_{1}^{2}$ & $1.98 \pm 0.20$ & & 6 & 9.2 & $15.2 \pm 0.65$ & & 0.44 & 1.22 & 0.32 & $0.63 \pm 0.05$ & & $3.62 \pm 0.54$ & \\
\hline & & $c_{1}$ & $1.64 \pm 0.16$ & 0.34 & 9.4 & 9 & $18.4 \pm 1.44$ & 3.2 & 1.01 & 1.11 & 0.51 & $1.03 \pm 0.08$ & $0.40^{\mathrm{b}}$ & $4.68 \pm 0.60$ & 1.06 \\
\hline & 200 & $\mathrm{~T}_{2}$ & $2.2 \pm 0.22$ & & 5. & 7 & $12 \pm 2.44$ & & 0.39 & 0.95 & 0.33 & $0.53 \pm 0.04$ & & $3.80 \pm 0.29$ & \\
\hline & & $\mathrm{C}_{2}$ & $1.48 \pm 0.10$ & $0.72^{\mathrm{a}}$ & 8.2 & 8.2 & $16.6 \pm 1.15$ & 4.6 & 0.91 & 0.96 & 0.53 & $0.93 \pm 0.11$ & $0.40^{\mathrm{b}}$ & $5.12 \pm 0.10$ & $1.32^{\mathrm{b}}$ \\
\hline
\end{tabular}

$a=p<0.05, b=p<0.0 I, c=p<0.00 I$ (significance levels of t-test) Mitotic Indices (MI) in 5000 cells ( 1000 cells from each individuals), Micronuclei in normochromatic erythrocytes (NCE) and polychromatic erythrocytes (PCE) in 5000 cells (I000 cells from each individuals) and Sperm headshape abnormality (SHA) in 5000 sperm ( 1000 sperm from each individuals) at different fixation intervals in $\mathrm{CdCl}_{2}$ treated mice pre-fed with Cad Sulph-30 $\left(T_{1}\right)$ and Cad Sulph-200 $\left(T_{2}\right)$ separately and respective alcohol-30 $\left(C_{1}\right)$ and alcohol-200 $\left(C_{2}\right)$ fed controls.

control with unsuccussed dilute alcohol was also used to be maintained, but since no significant difference was observed in the results between succussed alcohol fed series and dilute alcohol fed series, data of this control were not considered and incorporated in the present study for limiting the size of the tables.

One group (5 mice) of normal healthy mice were scanned for spontaneous levels of CA, MNE, MI and SHA, and another group (5 mice each), only fed with repeated doses of Cad sulph-30 or Cad sulph-200 at intervals corresponding to drug fed series, were also scanned for the same protocols.

\section{Laboratory methodology}

Chromosome aberration (CA) study

Chromosomes were prepared from the bone marrow cells by following the conventional colchicine-citrateflame-drying-Giemsa stain method. The nomenclature of Crippa [36] was followed in grouping the chromosomes into five size-classes.

Mitotic Index (MI) and Micronuclei (MNE) studies

For the study of MI and MNE, bone marrow cells of mice not treated with colchicine were centrifuged in $1 \%$ sodium citrate solution. The materials collected at the bottom were then smeared on clean grease free slides and allowed to air-dry. Air-dried slides were stained with May-Grunwald-Giemsa as per the conventional method $[37,38]$.

\section{Sperm head anomaly (SHA) study}

For the study of SHA, sperm collected from epididymis in normal saline. It was made free from fat, vas deferens and other tissue debries. Then the material was thoroughly shaken to make the sperm free to suspend in the saline solution. The sperm suspension was filtered, spread on clean grease-free slides, air dried and stained with Giemsa as per the routine technique [39]. 


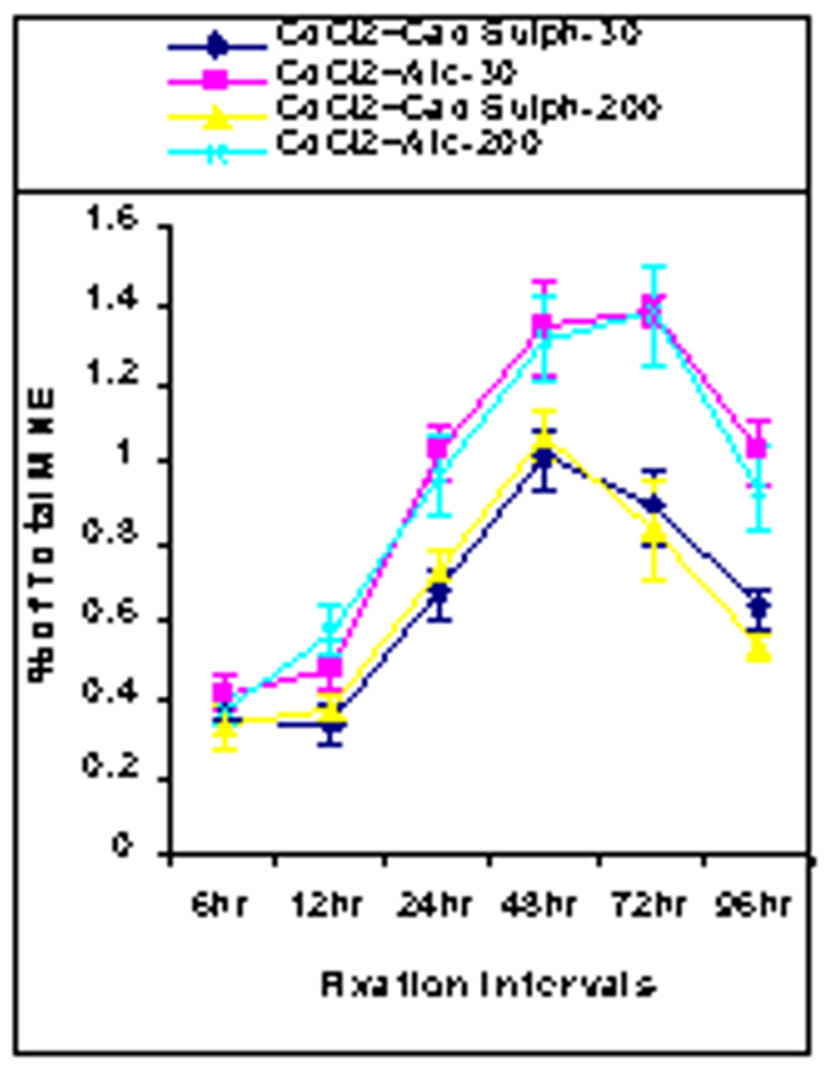

Figure 4

Showing time-dependent frequencies of Cad Sulph-30 prefed and Cad Sulph-200 pre-fed series versus their respective $\mathrm{CdCl}_{2}$ treated alcohol-30 and alcohol-200 control mice. Chromosome aberration (CA)-I; Mitotic index (MI)-2; Micronucleated erythrocytes (MNE)-3 and Sperm head anomaly (SHA)-4.

\section{Scoring of data}

The observer was "blinded" during observation and scoring of different parameters in the treated and control series to remove the possibility of any 'bias' during scoring of data.

\section{Statistical analysis}

The test of significance between the data of the experimental and control series was determined by Student's ttest and the analysis of variance (two way ANOVA). The levels of significance of $t$-values were determined according to Fisher and Yates [40] statistical tables.

\section{Results}

Qualitative changes

A single injection of $\mathrm{CdCl}_{2}$ induced various types of chromosome aberrations (CA) in bone marrow cells, a few representative types of which, namely, gap (Photomicrograph 1a), break (Photomicrograph 1b), fragment of un-

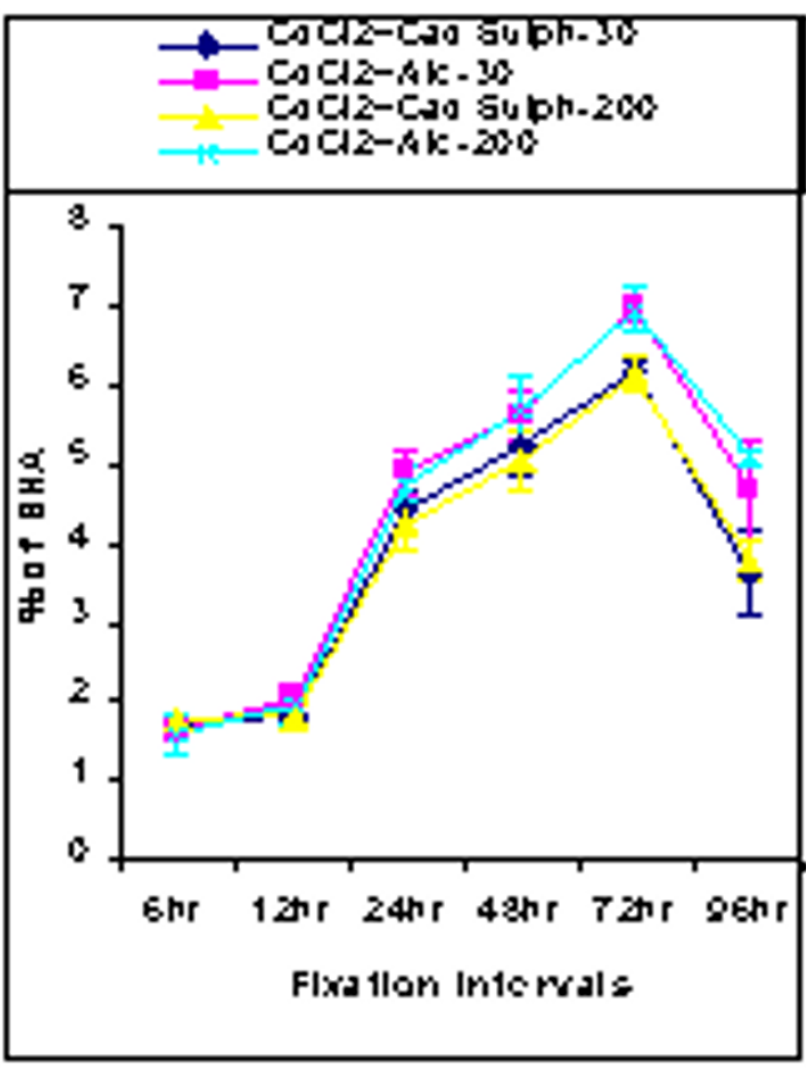

Figure 5

Showing time-dependent frequencies of Cad Sulph-30 prefed and Cad Sulph-200 pre-fed series versus their respective $\mathrm{CdCl}_{2}$ treated alcohol-30 and alcohol-200 control mice. Chromosome aberration (CA)-l; Mitotic index (MI)-2; Micronucleated erythrocytes (MNE)-3 and Sperm head anomaly (SHA)-4.

known origin (Photomicrograph 1c), terminal association (Photomicrograph 1d), ring and constriction (Photomicrograph 1e), precocious centromeric separation (Photomicrograph 1f), C-mitotic effect (Photomicrograph 1g), pulverisation (Photomicrograph $1 \mathrm{~h}$ ), erosion (Photomicrograph 1i) and polyploidy (Photomicrograph 1j) have been furnished. Micronucleated erythrocytes (MNE) - both polychromatic (Photomicrograph $1 \mathrm{k}$ ) and normochromatic (Photomicrograph 1l) were also found in certain bone marrow cells. Sperm with abnormal head-shapes (Sperm head anomaly-SHA) (Photomicrograph $1 \mathrm{~m}$ to 10) were also recorded.

\section{Quantitative changes}

The frequency distributions of CA, MNE, MI and SHA in all the drug-treated series vis-a-vis control series were analysed. In both the normal healthy mice and mice fed with Cad Sulph-30 and 200 in repeated doses, the frequencies of CA, MNE, abnormal sperm shapes and MI 
remained more or less within the spontaneous levels. Therefore, only the positive control (alcohol-30 or alcohol-200) was considered for comparison with the drug fed series for the sake of limiting the size of the tables and space.

\section{Chromosome aberrations (CA) study \\ Drug pre-fed series}

Both Cad Sulph-30 and Cad Sulph-200 could reduce the frequencies of CA in almost all the fixation intervals except for Cad Sulph-30 at $6 \mathrm{hr}$ and the reductions were quite significant in later intervals ( $p<0.05-p<0.001)$. The maximum protection was shown at $48 \mathrm{hr}$ in case of both the drugs after which the extent of protection declined. When the efficacy of two potencies was compared Cad Sulph-200 showed more protection in all the fixation intervals than that of Cad Sulph-30 (Table 1, Fig. 2).
Drug post-fed series

Both Cad Sulph-30 and Cad Sulph-200 could reduce the frequencies of $\mathrm{CA}$ in all the fixation intervals. Both the drugs showed maximum protection at $24 \mathrm{hr}$, after which it declined. Again Cad Sulph-20o showed more protection in all the fixation intervals than that of Cad Sulph-30 (Table 2, Fig. 6).

\section{Combined pre- and post-drug-fed series}

Both the drugs showed significant (except for $6 \mathrm{hr}$ ) protections in all the fixation intervals. Cad Sulph-20o showed more protection than that of Cad Sulph-30 (Table 3, Fig. 10).

When the modes of treatment were compared in respect of CA it was found that post treatment was more effective than that of pre-treatment and the combined pre and post treatment was the most effective as compared to the others.

Table 2: Frequency distribution of Chromosome Aberrations (CA) in 500 bone marrow cells examined ( 100 cells from each individuals).

\begin{tabular}{|c|c|c|c|c|c|c|c|c|c|c|c|c|c|c|c|}
\hline \multirow[b]{2}{*}{$\begin{array}{l}\text { Intervals } \\
\text { (hr) }\end{array}$} & \multirow[b]{2}{*}{$\begin{array}{l}\text { Drug } \\
\text { potency }\end{array}$} & \multirow[b]{2}{*}{ Series } & \multicolumn{2}{|c|}{ Mitotic Index } & \multicolumn{4}{|c|}{ Chromosome Aberration } & \multicolumn{5}{|c|}{ Micronucleated Erythrocyte } & \multicolumn{2}{|c|}{ Sperm Head Anomaly } \\
\hline & & & $\% \pm \mathrm{SE}$ & $\begin{array}{r}\% \text { of } \\
\text { Increased } \\
\mathrm{MI}\end{array}$ & $\begin{array}{r}\% \text { of } \\
\text { Major } \\
\text { CA }\end{array}$ & $\begin{array}{r}\% \text { of } \\
\text { Other } \\
\text { CA }\end{array}$ & $\begin{array}{r}\text { Total } \\
\mathrm{CA} \pm \mathrm{SE}\end{array}$ & Prot. & $\begin{array}{r}\% \text { of } \\
\mathrm{MN} \text { in } \\
\mathrm{NCE}\end{array}$ & $\begin{array}{r}\% \text { of } \\
M N \text { in } \\
P C E\end{array}$ & $\mathrm{P} / \mathrm{N}$ & $\begin{array}{r}\% \text { of } \\
\text { Total MN } \\
\text { in NCE } \\
\& \mathrm{PCE}\end{array}$ & $\begin{array}{l}\% \text { of } \\
\text { Prot, }\end{array}$ & $\begin{array}{r}\% \text { of } \\
S H A \pm S E\end{array}$ & $\begin{array}{l}\% \text { of } \\
\text { prot. }\end{array}$ \\
\hline \multirow[t]{4}{*}{6} & 30 & $\mathrm{~T}_{3}$ & $1.72 \pm 0.18$ & & 3.2 & 6 & $9.2 \pm 0.82$ & & 0.15 & 1.07 & 0.12 & $0.25 \pm 0.04$ & & $1.62 \pm 0.20$ & \\
\hline & & $C_{3}$ & $1.84 \pm 0.20$ & -0.12 & 3.8 & 7.4 & $11.2 \pm 0.96$ & 2.0 & 0.23 & 0.73 & 0.32 & $0.35 \pm 0.02$ & $0.10^{\mathrm{a}}$ & $1.68 \pm 0.25$ & 0.06 \\
\hline & 200 & $\mathrm{~T}_{4}$ & $1.98 \pm 0.23$ & & 3.4 & 5.2 & $8.6 \pm 1.20$ & & 0.2 & 0.67 & 0.13 & $0.25 \pm 0.04$ & & $1.48 \pm 0.19$ & \\
\hline & & $\mathrm{C}_{4}$ & $1.6 \pm 0.18$ & 0.38 & 5 & 6.6 & $11.6 \pm 1.44$ & 3.0 & 0.23 & 0.51 & 0.30 & $0.29 \pm 0.03$ & $0.04^{\mathrm{a}}$ & $1.56 \pm 0.18$ & 0.08 \\
\hline \multirow[t]{4}{*}{12} & 30 & $\mathrm{~T}_{3}$ & $1.84 \pm 0.14$ & & 6 & 6.8 & $12.8 \pm 0.82$ & & 0.2 & 0.58 & 0.25 & $0.27 \pm 0.04$ & & $1.64 \pm 0.18$ & \\
\hline & & $C_{3}$ & $1,36 \pm 0,17$ & 0.48 & 7.6 & 9.8 & $17.4 \pm 1.44$ & $4.6^{\mathrm{a}}$ & 0.43 & 0.64 & 0.45 & $0.49 \pm 0.05$ & $0.22^{\mathrm{a}}$ & $2.12 \pm 0.26$ & 0.48 \\
\hline & 200 & $\mathrm{~T}_{4}$ & $2.08 \pm 0.14$ & & 4.8 & 4.8 & $9.6 \pm 1.03$ & & 0.17 & 0.41 & 0.23 & $0.21 \pm 0.02$ & & $1.32 \pm 0.16$ & \\
\hline & & $\mathrm{C}_{4}$ & $1.38 \pm 0.19$ & $0.7^{\mathrm{a}}$ & 6.8 & 9.8 & $16.6 \pm 1.60$ & $7.0^{\mathrm{a}}$ & 0.4 & 0.57 & 0.45 & $0.47 \pm 0.06$ & $0.26^{a}$ & $2.04 \pm 0.23$ & $0.72^{\mathrm{a}}$ \\
\hline \multirow[t]{4}{*}{24} & 30 & $t_{3}$ & $1.7 \pm 0.33$ & & 8.2 & 9.4 & $17.6 \pm 1.52$ & & 0.54 & I & 0.31 & $0.65 \pm 0.05$ & & $3.6 \pm 0.24$ & \\
\hline & & $\mathrm{C}_{3}$ & $1.1 \pm 0.21$ & 0.6 & 15.2 & 14.6 & $29.8 \pm 1.55$ & $12.2^{c}$ & 0.81 & 1.44 & 0.28 & $0.95 \pm 0.08$ & $0.30^{\mathrm{a}}$ & $4.98 \pm 0.28$ & $1.38^{\mathrm{b}}$ \\
\hline & 200 & $\mathrm{~T}_{4}$ & $1.88 \pm 0.35$ & & 6.6 & 6.6 & $13.2 \pm 2.07$ & & 0.36 & 0.62 & 0.40 & $0.43 \pm 0.04$ & & $3.1 \pm 0.24$ & \\
\hline & & $\mathrm{C}_{4}$ & $0.98 \pm 0.22$ & 0.9 & 16.4 & 14.2 & $30.6 \pm 1.56$ & $17.4^{c}$ & 0.86 & 1.69 & 0.28 & $1.05 \pm 0.07$ & $0.62^{c}$ & $5.12 \pm 0.28$ & $2.02^{c}$ \\
\hline \multirow[t]{4}{*}{48} & 30 & $t_{3}$ & $2 \pm 0.16$ & & 7.8 & 9 & $16.8 \pm 0.77$ & & 0.54 & 0.76 & 0.45 & $0.61 \pm 0.08$ & & $4.56 \pm 0.39$ & \\
\hline & & $\mathrm{C}_{3}$ & $0.98 \pm 0.14$ & $1.02^{\mathrm{b}}$ & 11 & 12.8 & $23.8 \pm 1.34$ & $7.0^{\mathrm{b}}$ & 1.34 & 1.28 & 0.54 & $1.32 \pm 0.08$ & $0.7 I^{c}$ & $5.9 \pm 0.41$ & $1.34^{\mathrm{a}}$ \\
\hline & 200 & $\mathrm{~T}_{4}$ & $2.34 \pm 0.16$ & & 7 & 7.4 & $14.4 \pm 0.90$ & & 0.32 & 0.41 & 0.50 & $0.35 \pm 0.02$ & & $4.06 \pm 0.39$ & \\
\hline & & $\mathrm{C}_{4}$ & $1.06 \pm 0.13$ & $1.28^{c}$ & 12 & 13.8 & $25.8 \pm 0.96$ & $11.4^{\mathrm{c}}$ & 1.15 & 1.41 & 0.50 & $1.22 \pm 0.04$ & $0.87^{c}$ & $6.02 \pm 0.38$ & $1.96^{\mathrm{b}}$ \\
\hline \multirow[t]{4}{*}{72} & 30 & $t_{3}$ & $2.76 \pm 0.21$ & & 5.6 & 7.2 & $12.8 \pm 1.38$ & & 0.47 & 0.64 & 0.33 & $0.51 \pm 0.06$ & & $7.64 \pm 0.16$ & \\
\hline & & $\mathrm{C}_{3}$ & $1.7 \pm 0.18$ & $1.06^{b}$ & 9.6 & 10.4 & $20 \pm 1.45$ & $7.2^{\mathrm{b}}$ & 1.65 & 1.06 & 0.58 & $1.44 \pm 0.09$ & $0.93^{c}$ & $7.74 \pm 0.30$ & 0.10 \\
\hline & 200 & $\mathrm{~T}_{4}$ & $2.9 \pm 0.22$ & & 6.6 & 4.4 & $\mathrm{II} \pm \mathrm{I} .50$ & & 0.26 & 0.59 & 0.30 & $0.33 \pm 0.05$ & & $4.86 \pm 0.33$ & \\
\hline & & $\mathrm{C}_{4}$ & $1.56 \pm 0.07$ & $1.34^{c}$ & 9.4 & 11.2 & $20.6 \pm 1.64$ & $9.6^{c}$ & 1.17 & 1.62 & 0.60 & $1.32 \pm 0.08$ & $0.99 c$ & $7.28 \pm 0.20$ & $2.42^{c}$ \\
\hline \multirow[t]{4}{*}{96} & 30 & $t_{3}$ & $2.3 \pm 0.23$ & & 4.6 & 7.6 & $12.2 \pm 1.14$ & & 0.28 & 0.92 & 0.17 & $0.37 \pm 0.06$ & & $2.72 \pm 0.18$ & \\
\hline & & $\mathrm{C}_{3}$ & $1.26 \pm 0.15$ & $1.04 c$ & 8.2 & 10.2 & $18.4 \pm 1.60$ & $6.2^{\mathrm{a}}$ & 0.86 & 0.94 & 0.49 & $0.91 \pm 0.09$ & $0.54^{c}$ & $4.64 \pm 0.34$ & $1.92^{b}$ \\
\hline & 200 & $\mathrm{~T}_{4}$ & $2.56 \pm 0.26$ & & 3.2 & 5.6 & $9.8 \pm 1.24$ & & 0.18 & 0.71 & 0.16 & $0.25 \pm 0.02$ & & $2.38 \pm 0.24$ & \\
\hline & & $\mathrm{C}_{4}$ & $1.42 \pm 0.10$ & $1.14^{b}$ & 7.4 & 10.4 & $17.6 \pm 1.60$ & $7.8^{b}$ & 0.94 & 1.01 & 0.49 & $0.97 \pm 0.09$ & $0.72^{c}$ & $5.14 \pm 0.19$ & $2.76^{\mathrm{C}}$ \\
\hline
\end{tabular}

$a=p<0.05, b=p<0.01, c=p<0.001$ (significance levels of t-test) Mitotic Indices (MI) in 5000 cells (I 000 cells from each individuals), Micronuclei in normochromatic erythrocytes (NCE) and polychromatic erythrocytes (PCE) in 5000 cells (I000 cells from each individuals) and Sperm headshape abnormality (SHA) in 5000 sperm ( 1000 sperm from each individuals) at different fixation intervals in $\mathrm{CdCl}_{2}$ treated mice post-fed with Cad Sulph-30 $\left(\mathrm{T}_{3}\right)$ and Cad Sulph-200 $\left(\mathrm{T}_{4}\right)$ separately and respective alcohol-30 $\left(\mathrm{C}_{3}\right)$ and alcohol-200 $\left(\mathrm{C}_{4}\right)$ fed controls. 
Table 3: Frequency distribution of Chromosome Aberrations (CA) in 500 bone marrow cells examined ( 100 cells from each individuals).

\begin{tabular}{|c|c|c|c|c|c|c|c|c|c|c|c|c|c|c|c|}
\hline \multirow[b]{2}{*}{$\begin{array}{l}\text { Intervals } \\
\text { (hr) }\end{array}$} & \multirow[b]{2}{*}{$\begin{array}{l}\text { Drug } \\
\text { potency }\end{array}$} & \multicolumn{3}{|c|}{ Mitotic Index } & \multicolumn{4}{|c|}{ Chromosome Aberration } & \multicolumn{5}{|c|}{ Micronucleated Erythrocyte } & \multicolumn{2}{|c|}{ Sperm Head Anomaly } \\
\hline & & & $\% \pm \mathrm{SE}$ & $\begin{array}{r}\% \text { of } \\
\text { Increased } \\
\text { MI. }\end{array}$ & $\begin{array}{r}\% \text { of } \\
\text { Major } \\
\text { CA }\end{array}$ & $\begin{array}{r}\% \text { of } \\
\text { Other } \\
\text { CA }\end{array}$ & $\begin{array}{r}\% \text { of Total } \\
C A \pm S E\end{array}$ & $\begin{array}{l}\% \text { of } \\
\text { Prot. }\end{array}$ & $\begin{array}{r}\% \text { of } \\
M N \text { in } \\
\text { NCE }\end{array}$ & $\begin{array}{r}\% \text { of } \\
M N \text { in } \\
\text { PCE }\end{array}$ & $\mathrm{P} / \mathrm{N}$ & $\begin{array}{r}\% \text { of } \\
\text { Total MN } \\
\text { in NCE } \\
\& \mathrm{PCE}\end{array}$ & $\begin{array}{l}\% \text { of } \\
\text { Prot. }\end{array}$ & $\begin{array}{r}\% \text { of } \\
\text { SHA } \pm \text { SE }\end{array}$ & $\begin{array}{l}\% \text { of } \\
\text { prot. }\end{array}$ \\
\hline \multirow[t]{4}{*}{6} & 30 & $\mathrm{~T}_{5}$ & $1.84 \pm 0.22$ & & 3.4 & 5.4 & $8.8 \pm 1.14$ & & 0.15 & 0.58 & 0.11 & $0.21 \pm 0.02$ & & $1.6 \pm 0.15$ & \\
\hline & & $\mathrm{C}_{5}$ & $1.42 \pm 0.14$ & 0.42 & 4.4 & 6 & $10.4 \pm 1.82$ & 1.6 & 0.31 & 0.72 & 0.33 & $0.41 \pm 0.04$ & $0.20^{a}$ & $1.64 \pm 0.07$ & 0.04 \\
\hline & 200 & $\mathrm{~T}_{6}$ & $2.1 \pm 0.25$ & & 2 & 3 & $5 \pm 1.17$ & & 0.14 & 0.7 & 0.24 & $0.22 \pm 0.05$ & & $1.72 \pm 0.17$ & \\
\hline & & $\mathrm{C}_{6}$ & $1.48 \pm 0.16$ & 0.62 & 4.2 & 4.6 & $10.8 \pm 1.14$ & 5.8 & 0.33 & 1.06 & 0.51 & $0.48 \pm 0.05$ & $0.26^{b}$ & $1.5 \pm 0.12$ & -0.22 \\
\hline \multirow[t]{4}{*}{12} & 30 & $\mathrm{~T}_{5}$ & $2.24 \pm 0.12$ & & 4.8 & 6.4 & $11.2 \pm 0.65$ & & 0.16 & 0.59 & 0.20 & $0.27 \pm 0.02$ & & $1.7 \pm 0.22$ & \\
\hline & & $C_{5}$ & $1.56 \pm 0.13$ & $0.68^{b}$ & 8 & 9.4 & $17.4 \pm 1.68$ & $6.2^{b}$ & 0.43 & 0.77 & 0.49 & $0.55 \pm 0.05$ & $0.32^{c}$ & $2.16 \pm 0.28$ & $0.46^{a}$ \\
\hline & 200 & $T_{6}$ & $2.42 \pm 0.12$ & & 3 & 4.8 & $7.4 \pm 0.74$ & & 0.14 & 0.38 & 0.18 & $0.17 \pm 0.02$ & & $1.52 \pm 0.19$ & \\
\hline & & $C_{6}$ & $1.46 \pm 0.13$ & $0.96 \mathrm{c}$ & 5.8 & 10.2 & $16 \pm 1.54$ & $8.2^{c}$ & 0.36 & 0.81 & 0.45 & $0.51 \pm 0.04$ & $0.34 c$ & $2.12 \pm 0.21$ & 0.6 \\
\hline \multirow[t]{4}{*}{24} & 30 & $\mathrm{~T}_{5}$ & $2.04 \pm 0.18$ & & 6.0 & 6.6 & $12.6 \pm 1.2$ & & 0.31 & I & 0.31 & $0.47 \pm 0.04$ & & $3.02 \pm 0.19$ & \\
\hline & & $\mathrm{C}_{5}$ & $\mathrm{I} . \mathrm{I} \pm 0.20$ & $0.94 b$ & 14.6 & 15.6 & $30.2 \pm 1.63$ & $17.6 \mathrm{c}$ & 0.91 & 1.81 & 0.32 & $1.12 \pm 0.08$ & $0.77 c$ & $5.09 \pm 0.30$ & $2.07 c$ \\
\hline & 200 & $T_{6}$ & $2.28 \pm 0.26$ & & 4.8 & 5.6 & $10.4 \pm 1.30$ & & 0.18 & 0.47 & 0.32 & $0.25 \pm 0.02$ & & $2.64 \pm 0.23$ & \\
\hline & & $\mathrm{C}_{6}$ & $0.98 \pm 0.17$ & $1.3^{b}$ & 13.4 & 18.4 & $31.8 \pm 1.55$ & $21.4 \mathrm{c}$ & 0.87 & 1.72 & 0.30 & $1.05 \pm 0.10$ & $0.80 c$ & $4.96 \pm 0.57$ & $2.32^{b}$ \\
\hline \multirow[t]{4}{*}{48} & 30 & $\mathrm{~T}_{5}$ & $2.44 \pm 0.09$ & & 5.6 & 5.8 & $11.4 \pm 1.03$ & & 0.36 & 0.53 & 0.51 & $0.41 \pm 0.06$ & & $3.64 \pm 0.29$ & \\
\hline & & $\mathrm{C}_{5}$ & $1.44 \pm 0.20$ & lb & 12.4 & 13.6 & $26 \pm 1.87$ & $14.6 \mathrm{c}$ & 0.98 & 1.63 & 0.46 & $1.20 \pm 0.04$ & 0.79 & $5.64 \pm 0.34$ & $2^{b}$ \\
\hline & 200 & $\mathrm{~T}_{6}$ & $2.84 \pm 0.16$ & & 5.0 & 5.8 & $10.8 \pm 1.14$ & & 0.12 & 0.44 & 0.55 & $0.23 \pm 0.02$ & & $3.38 \pm 0.35$ & \\
\hline & & $\mathrm{C}_{6}$ & $1.16 \pm 0.13$ & $1.68^{c}$ & 13.0 & 14 & $27 \pm 1.11$ & $16.2^{c}$ & 1.06 & 1.56 & 0.49 & $1.22 \pm 0.05$ & $0.99 c$ & $5.74 \pm 0.32$ & $2.36^{\mathrm{b}}$ \\
\hline \multirow[t]{4}{*}{72} & 30 & $\mathrm{~T}_{5}$ & $2.86 \pm 0.14$ & & 3.2 & 5.6 & $8.8 \pm 1.14$ & & 0.7 & 1.23 & 0.46 & $0.89 \pm 0.09$ & & $4.72 \pm 0.23$ & \\
\hline & & $\mathrm{C}_{5}$ & $1.68 \pm 0.09$ & $1.18 \mathrm{c}$ & 8.0 & 9.4 & $|7.4 \pm| .5 \mid$ & $8.6^{c}$ & 1.21 & 1.64 & 0.57 & $1.38 \pm 0.04$ & $0.49 c$ & $7.06 \pm 0.24$ & $2.34 \mathrm{c}$ \\
\hline & 200 & $T_{6}$ & $3.18 \pm 0.28$ & & 3.6 & 4.8 & $8.4 \pm 1.33$ & & 0.12 & 0.55 & 0.27 & $0.21 \pm 0.04$ & & $5.38 \pm 0.20$ & \\
\hline & & $\mathrm{C}_{6}$ & $1.6 \pm 0.09$ & $1.58 \mathrm{c}$ & 9.0 & 12.4 & $21.4 \pm 1.30$ & $13^{c}$ & 1.45 & 0.64 & 0.64 & $1.38 \pm 0.09$ & $1.17 c$ & $7.96 \pm 0.35$ & $2.58^{\mathrm{c}}$ \\
\hline \multirow[t]{4}{*}{96} & 30 & $\mathrm{~T}_{5}$ & $2.68 \pm 0.24$ & & 3.8 & 4.8 & $8.6 \pm 0.90$ & & 0.27 & 0.69 & 0.29 & $0.37 \pm 0.02$ & & $2.18 \pm 0.15$ & \\
\hline & & $\mathrm{C}_{5}$ & $1.68 \pm 0.13$ & $1.00^{b}$ & 9.2 & 10 & $19.2 \pm 1.55$ & $10.6 \mathrm{c}$ & 1.18 & 1.34 & 0.46 & $1.20 \pm 0.04$ & $0.83 c$ & $4.88 \pm 0.30$ & $2.7 c$ \\
\hline & 200 & $T_{6}$ & $3 \pm 0.23$ & & 3.6 & 4.4 & $8 \pm 0.61$ & & 0.15 & 0.29 & 0.29 & $0.23 \pm 0.02$ & & $1.86 \pm 0.13$ & \\
\hline & & $\mathrm{C}_{6}$ & $1.58 \pm 0.13$ & $1.42^{b}$ & 9.0 & 9.8 & $|8.8 \pm 1.3|$ & $10.8 \mathrm{c}$ & 1.06 & 0.45 & 0.45 & $1.10 \pm 0.07$ & $0.87 c$ & $5.02 \pm 0.14$ & $3.16^{c}$ \\
\hline
\end{tabular}

$a=p<0.05, b=p<0.01, c=p<0.001$ (significance levels of t-test) Mitotic Indices (MI) in 5000 cells ( 1000 cells from each individuals), Micronuclei in normochromatic erythrocytes (NCE) and polychromatic erythrocytes (PCE) in 5000 cells (I000 cells from each individuals) and Sperm headshape abnormality (SHA) in 5000 sperm ( 1000 sperm from each individuals) at different fixation intervals in $\mathrm{CdCl}_{2}$ treated mice combined pre- and post-fed with Cad Sulph-30 ( $\left.T_{5}\right)$ and Cad Sulph-200 ( $\left.T_{6}\right)$ separately and respective alcohol-30 $\left(C_{5}\right)$ and alcohol-200 $\left(C_{6}\right)$ fed controls.

\section{Mitotic Index (MI) study}

Drug pre-fed series

Both Cad Sulph-30 and Cad Sulph-20o could enhance the frequencies of MI in all the fixation intervals and the maximum enhancement was shown at the later intervals (24-96 hr). When the efficacy of two drugs were compared Cad Sulph-200 showed more enhancement of MI than that of Cad Sulph-30 in almost all the fixation intervals except for $72 \mathrm{hr}$ where it was just the opposite (Table 1, Fig. 3).

\section{Drug post-fed series}

Both the drugs could enhance the frequencies of MI in all the fixation intervals and the maximum enhancement was shown at $72 \mathrm{hr}(\mathrm{p}<0.01$ in case of Cad sulph-30 and $\mathrm{p}<0.001$ in case of Cad sulph-200). Again when the efficacy of two drugs were compared Cad Sulph-200 showed more enhancement of MI than that of Cad Sulph-30 in all the fixation intervals (Table 2, Fig. 7).
Combined pre and post drug-fed series

Both the drugs showed increase in MI at all the fixation intervals and those were statistically significant except for $6 \mathrm{hr}$. Further, Cad Sulph-200 increased MI more than that of Cad Sulph-30 (Table 3, Fig. 11).

When the modes of treatment were compared in respect of MI, it was found that post treatment was more effective than that of pre-treatment and the combined preand post-treatment was the most effective.

\section{Micronuclei (MN) study}

\section{Drug pre-fed series}

Both Cad Sulph-30 and Cad Sulph-200 could reduce the frequencies of NCE, PCE and total MNE in all the fixation intervals. The maximum protection was shown at 24 $\mathrm{hr}$ in case of both the drugs and after that it declined. When the efficacy of two drugs was compared Cad Sulph200 showed more protection in all the fixation intervals than that of Cad Sulph-3o (Table 1, Fig. 4). 


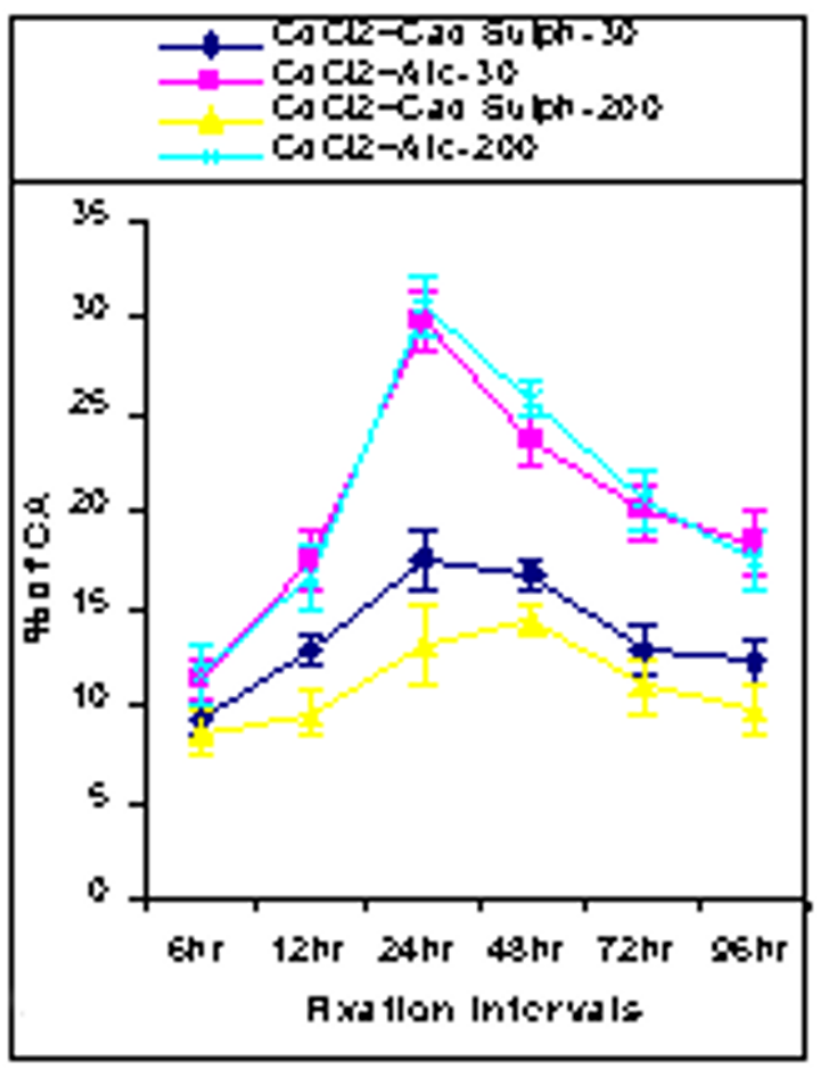

Figure 6

Showing time-dependent frequencies of Cad Sulph-30 postfed and Cad Sulph-200 post-fed series versus their respective $\mathrm{CdCl}_{2}$ treated alcohol-30 and alcohol-200 control mice. Chromosome aberration (CA)-5; Mitotic index (MI)-6; Micronucleated erythrocytes (MNE)-7 and Sperm head anomaly (SHA)-8.

Drug post-fed series

Both the drugs could reduce the frequencies of NCE, PCE and total MNE in all the fixation intervals and the differences were statistically significant in almost all the fixation intervals (except for Cad Sulph-200 at $6 \mathrm{hr}$ ). Cad Sulph-200 showed more protective ability than that of Cad Sulph-30 (Table 2, Fig. 8).

Combined pre and post drug-fed series

Both the potencies showed remarkable efficiency in reducing the frequencies of NCE, PCE and total MNE in all the fixation intervals and the differences were statistically highly significant ( $\mathrm{p}<$ 0.001). Cad Sulph-200 showed more protection than Cad Sulph-30 (Table 3, Fig. 12).

When the modes of treatment were compared it was noticed that both the drugs could show more protection in combined pre- and post-feeding followed by only postfeeding.

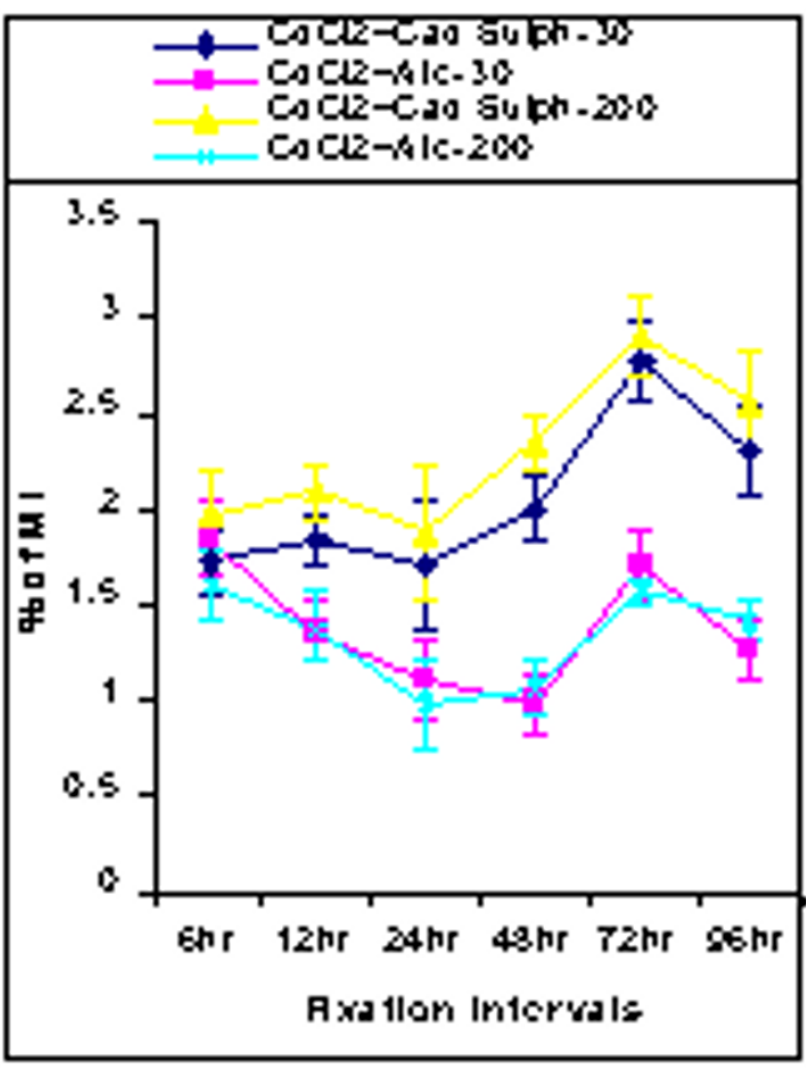

Figure 7

Showing time-dependent frequencies of Cad Sulph-30 postfed and Cad Sulph-200 post-fed series versus their respective $\mathrm{CdCl}_{2}$ treated alcohol-30 and alcohol-200 control mice. Chromosome aberration (CA)-5; Mitotic index (MI)-6; Micronucleated erythrocytes (MNE)-7 and Sperm head anomaly (SHA)-8.

\section{Sperm head anomaly (SHA) study}

Drug pre-fed series

Both Cad Sulph-30 and 200 could reduce the frequencies of sperm with abnormal head shapes in almost all the fixation intervals except for $6 \mathrm{hr}$ and the $200^{\text {th }}$ potency showed more protection than that of the $30^{\text {th }}$ potency (Table 1, Fig. 5).

Drug post-fed series

Both the potencies showed reductions in frequencies of sperm with abnormal head shapes in all the fixation intervals and the differences were statistically significant in almost all the fixation intervals except for $6 \mathrm{hr}$. Cad Sulph-200 showed more protective ability than that of Cad Sulph-30 (Table 2, Fig. 6).

Combined pre and post drug-fed series

The same trend was noticed for both potencies of the drug (except for Cad Sulph-200 at 6 hr) (Table 3, Fig. 13). 




Figure 8

Showing time-dependent frequencies of Cad Sulph-30 postfed and Cad Sulph-200 post-fed series versus their respective $\mathrm{CdCl}_{2}$ treated alcohol-30 and alcohol-200 control mice. Chromosome aberration (CA)-5; Mitotic index (MI)-6; Micronucleated erythrocytes (MNE)-7 and Sperm head anomaly (SHA)-8.

The maximum protective ability of both potencies of the drug was noticed in combined pre- and post-feeding followed by post-and pre-feeding.

\section{Discussion}

From the results of the present investigation it is revealed that both Cad Sulph-30 and Cad Sulph-200 showed remarkable potential to reduce genotoxic effects produced by $\mathrm{CdCl}_{2}$ although the drug itself had no palpable genotoxic effects of its own when fed to normal healthy mice. Incidentally the results were essentially similar to different potencies of Ars Alb used against arsenic poisoning [30-35,41,42]. It would also be revealed clearly that Cad sulph-200 rendered more pronounced protective effect, particularly at longer fixation intervals.

Cadmium poisoning in certain areas, particularly at or near Zinc mines and Zinc processing factories, paint industries, has crossed tolerable limits. Incidentally, cad-

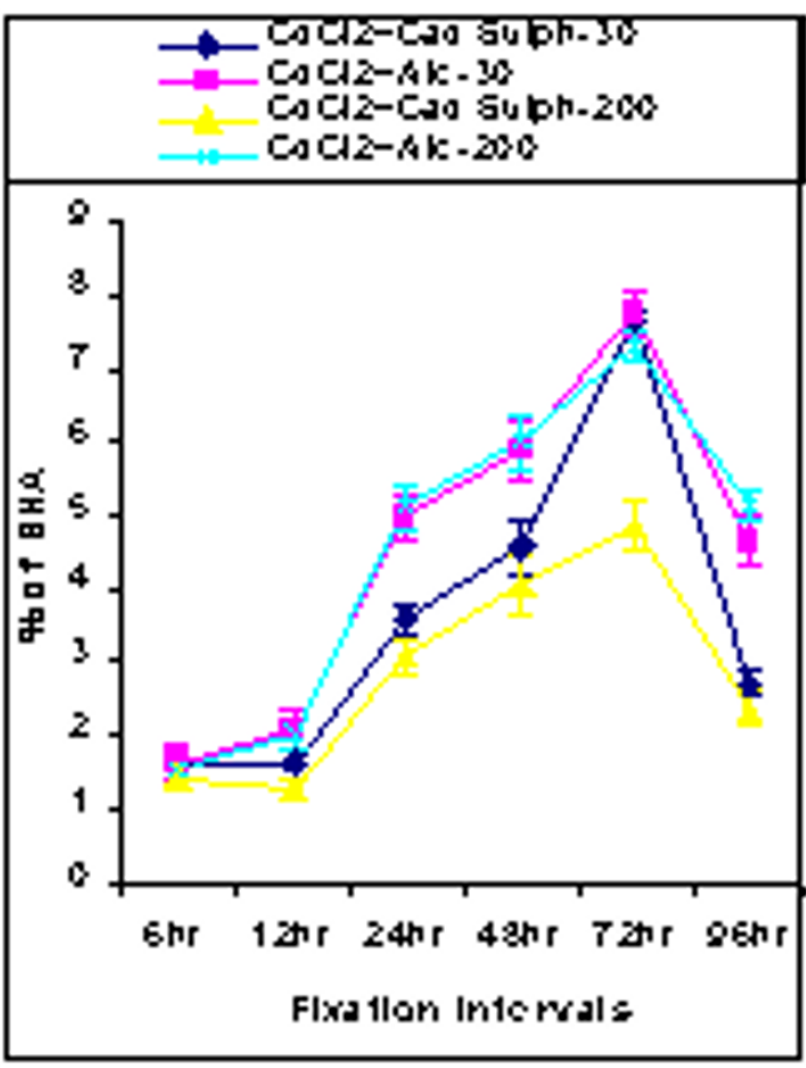

Figure 9

Showing time-dependent frequencies of Cad Sulph-30 postfed and Cad Sulph-200 post-fed series versus their respective $\mathrm{CdCl}_{2}$ treated alcohol-30 and alcohol-200 control mice. Chromosome aberration (CA)-5; Mitotic index (MI)-6; Micronucleated erythrocytes (MNE)-7 and Sperm head anomaly (SHA)-8.

mium has been reported to significantly inhibit $E$. coli and human DNA polymerase activity $[43,44]$. When growing cultures of $E$. coli were exposed to cadmium, considerable single-strand breaks were reported to occur in DNA [45]. Further, Privezentsev et al[46] reported that cadmium genotoxicity observed in both in vivo and in vitro cells of mice would be due to single-strand breaks in DNA through the direct cadmium-DNA interactions. In our present study also, we noted quite a good number of plates with clear chromosomal damage indicative of DNA breaks and other forms of lesions. Therefore, the search for a protective agent which may be used without any fear or risk of toxic side effects to prevent/ repair such damages seemed to us to be important. From the encouraging and positive modulating action of the potentized Cad Sulph observed in the present study, these drugs could be suggested as strong candidates for combating unintentional/accidental exposure to sub- 


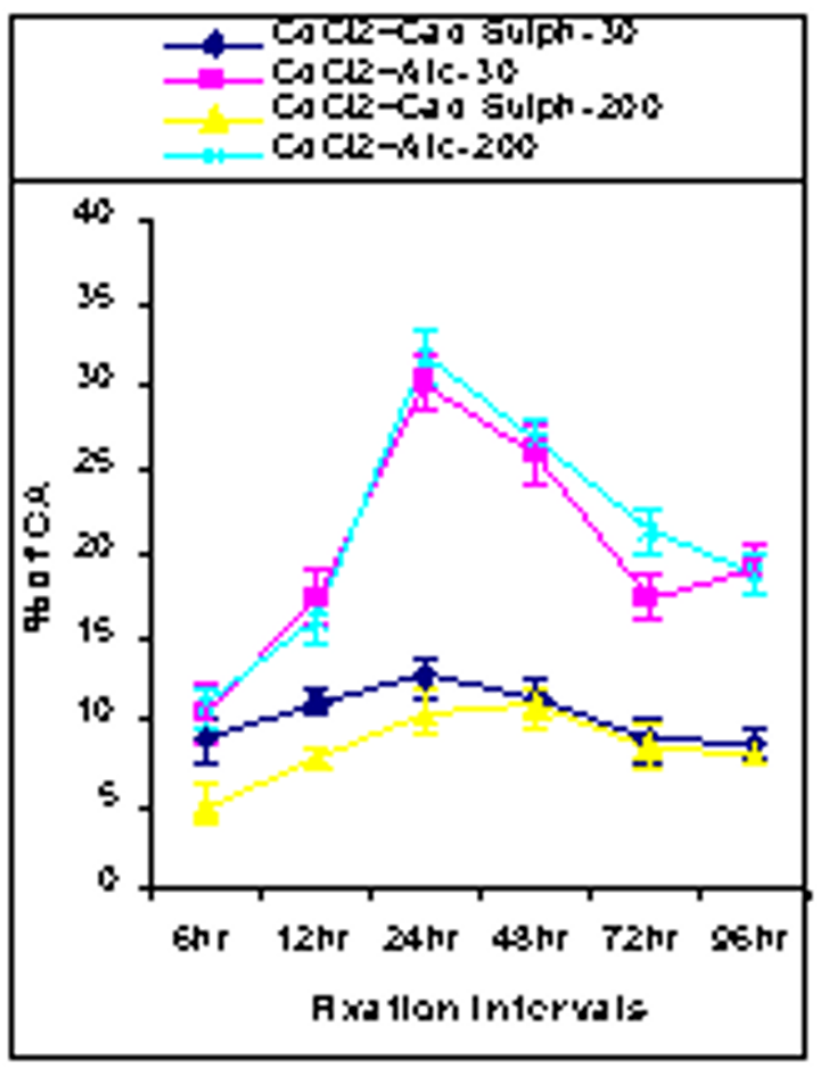

Figure 10

Showing time-dependent frequencies of Cad Sulph-30 combined pre- and post-fed and Cad Sulph-200 combined preand post-fed series versus their respective $\mathrm{CdCl}_{2}$ treated alcohol-30 and alcohol-200 control mice. Chromosome aberration (CA)-9; Mitotic index (MI)-I0; Micronucleated erythrocytes (MNE)-II and Sperm head anomaly (SHA)- I 2.

acute cadmium poisoning, both as a preventive as well as curative agent.

In the present study the homeopathic drug apparently enhanced/activated the process of maintaining the structural integrity of chromosomes and sperm either protecting them from the destructive ability of $\mathrm{CdCl}_{2}$ in causing DNA damage or else, by enhancing the process of repair of DNA already damaged by activating specific enzyme systems to repair the damage.

Incidentally, there are inherent mechanisms of DNA and chromosome repairs $[47,48]$ which are known to be genetically controlled. The same is true for the regulation of cell cycle events. In the present study also we have noted a positive shift in the mitotic index in the $\mathrm{CdCl}_{2}$-fed mice which may be linked to the replenishment of bone marrow cells, the necessity arising out of the exclusion/loss of damaged marrow cells due to the toxic chemical inter-

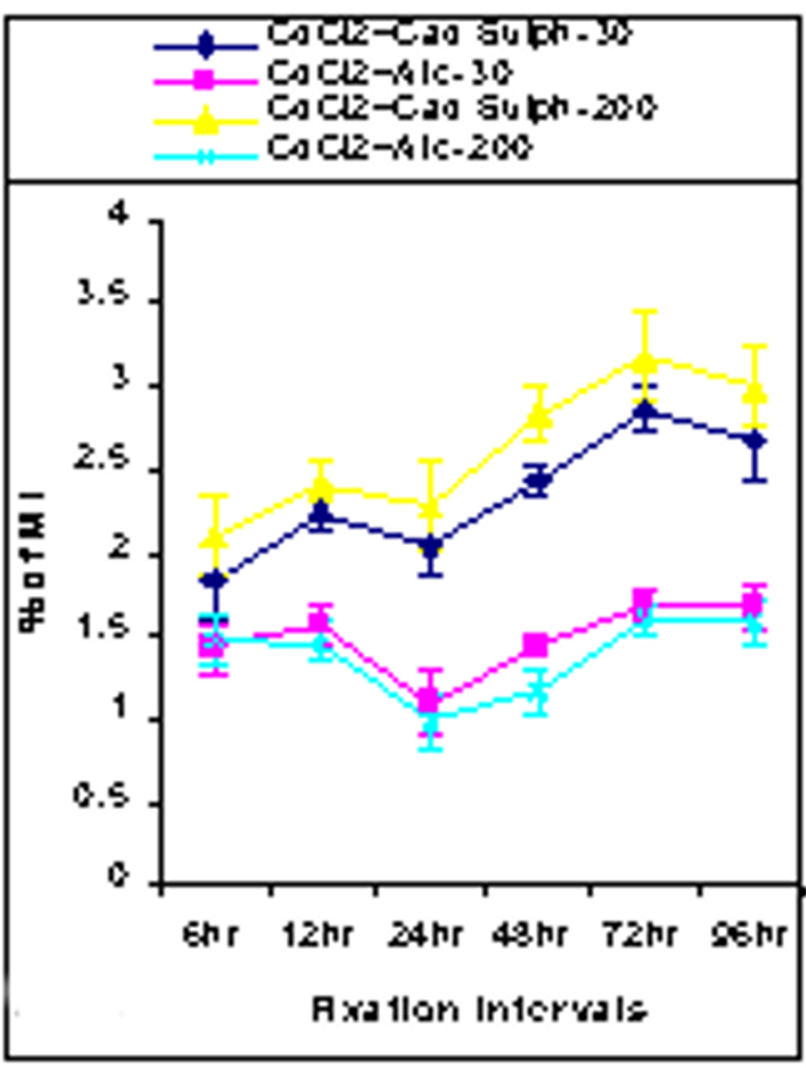

Figure I I

Showing time-dependent frequencies of Cad Sulph-30 combined pre- and post-fed and Cad Sulph-200 combined preand post-fed series versus their respective $\mathrm{CdCl}_{2}$ treated alcohol-30 and alcohol-200 control mice. Chromosome aberration (CA)-9; Mitotic index (MI)-10; Micronucleated erythrocytes (MNE)-II and Sperm head anomaly (SHA)- I 2.

action of $\mathrm{CdCl}_{2}$ to chromosome components primarily made up of DNA and protein. The repair mechanisms of chromosomes, therefore, also involved inherent mechanisms for repair of protein damage, a process also under a precise genetical control [47-49]. Therefore, any mechanism that can repair/protect cytogenetical effects must necessarily be regulated by specific genetic mechanisms essentially controlled by specific genes. Theoretically speaking even in the absence of a single original drug molecule both Cad Sulph-30 and 200 elicited spectacular ability of protection/repair to damaged chromosomes and sperm, a fact which would lead one to speculate that the drugs must have acted through the genetic regulatory mechanisms. In fact, Khuda-Bukhsh [50] explained the possible mechanism of action of the potentized homeopathic drugs by suggesting that one major way by which the potentized homeopathic drugs acted was possibly through regulation of expression of certain genes. This could be achieved by activating cer- 


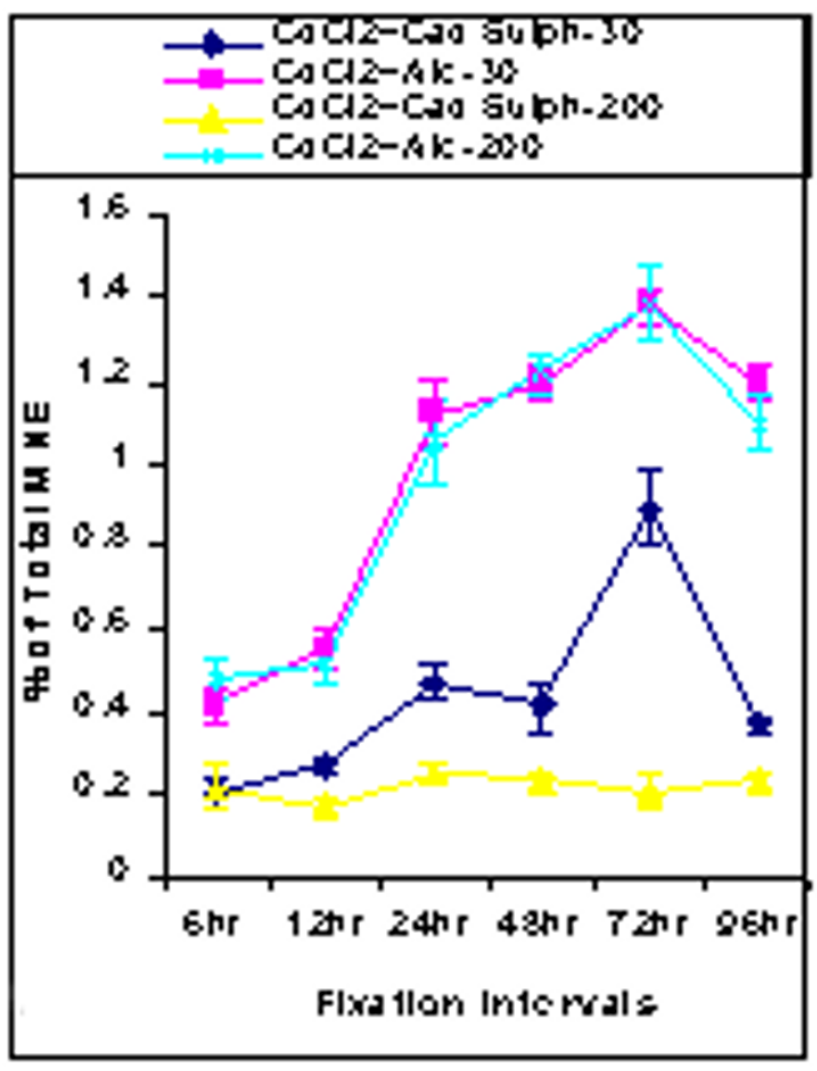

Figure 12

Showing time-dependent frequencies of Cad Sulph-30 combined pre- and post-fed and Cad Sulph-200 combined preand post-fed series versus their respective $\mathrm{CdCl}_{2}$ treated alcohol-30 and alcohol-200 control mice. Chromosome aberration (CA)-9; Mitotic index (MI)-I0; Micronucleated erythrocytes (MNE)-II and Sperm head anomaly (SHA)- I 2.

tain hormones and enzymes through transduction of specific regulatory signals including transcription factors (either inducive or repressive in nature) on target cells, in order to get them back to their normal state of functioning. The results of this study will also strengthen this view.

\section{Conclusion}

In conclusion, it may be pointed out that the two microdoses of Cad Sulph were capable of rendering protection/repair to the genotoxic damages caused by the treatment of the toxic chemical, $\mathrm{CdCl}_{2}$, and these were most effective when the combined pre- and post-feeding mode was followed. However, only post-feeding also proved to be effective in restoring the damages to a considerable extent. Interesting to note, however, is the fact that the more diluted, or the $200^{\text {th }}$ potency appeared to have more pronounced efficacy in rendering protective effects than that of the $30^{\text {th }}$ potency, as is claimed in the

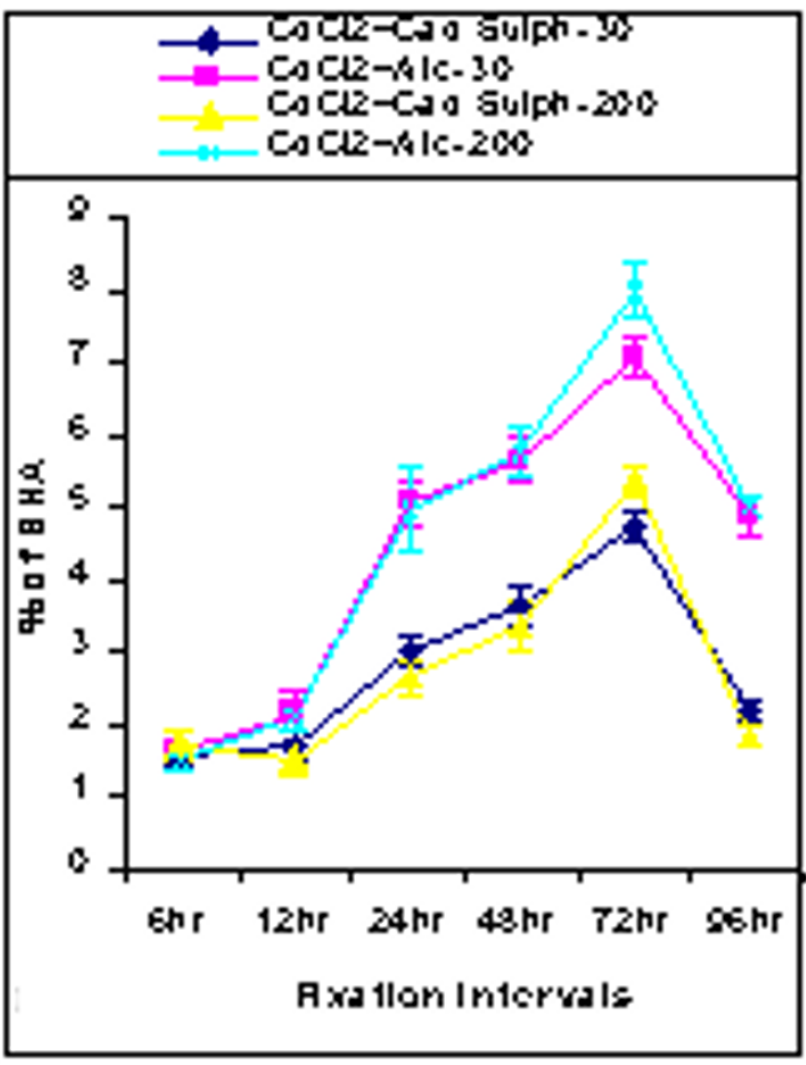

Figure 13

Showing time-dependent frequencies of Cad Sulph-30 combined pre- and post- fed and Cad Sulph-200 combined preand post-fed series versus their respective $\mathrm{CdCl}_{2}$ treated alcohol-30 and alcohol-200 control mice. Chromosome aberration (CA)-9; Mitotic index (MI)-I0; Micronucleated erythrocytes (MNE)-II and Sperm head anomaly (SHA)- 12.

homeopathic literature. Since there is also some amount of protective effects of Cad Sulph against $\mathrm{CdCl}_{2}$ poisoning, and since combined pre- and post-feeding mode appeared to show the maximum protective effect, and since Cad Suplh itself had no damaging effects of its own on the genome, the preventive administration of Cad Suplh to people living in contaminated zone may be considered.

\section{Acknowledgement}

Grateful acknowledgements are made to CRIJAF, Barrackpore, Institute of Health and Hygiene, Calcutta for help in collecting the references and to University of Kalyani, for partial financial support of the work.

\section{References}

I. Nilsson R: Aspects on the toxicity of cadmium and its compounds, a review. Bull Ecol Res Commun 1970, 4:1-58

2. Page A, Bingham F: Cadmium residues in the environment. Residue Rev 1973, 48: I-44

3. Fishbein L: Mutagens and potential mutagens in the biosphere, 2, Metals: mercury, lead, cadmium and tin. Sci Total Environ 1974, 2:34|-37| 
4. Fishbein L: Environmental metallic carcinogens: An overview of exposure levels. J Toxicol Environ Health 1976, 2:77-106

5. Friberg L, Piscator M, Nordberg GF, Kjellstorm T: Cadmium in the Environment. CRC Press, Cleveland 1974

6. Fassette D: Cadmium biological effects and occurrence in the environment. Ann Rev Pharmacol 1975, I 5:425-435

7. Neathery M, Miller W: Metabolism and toxicity of cadmium, mercury and lead in animal: A review. J Dairy Sci 1976, 58:1767|78|

8. DiFerrante I: Trace Metals: Exposure and Health Effects. Pergamon Press 1979

9. Kjellstrom T: Exposure and accumulation of cadmium in populations from Japan, USA and Sweden. Environ Health Pers 1979, 28:169-197

10. Webb M: The Chemistry, Biochemistry and Biology of Cadmium. Elsevier, Amsterdam 1979

II. Gunn S, Gould T, Anderson W: Cadmium induced interstitial cell tumours in rats and mice and their prevention by zinc. J Natl Cancer Inst 1963, 31:745-759

12. Haddow A, Roc F, Dukes C, Mitchley B: Cadmium neoplasia: sareometa at the site of injection of cadmium sulphate in rats and mice. Br J Cancer 1964, I8:667-673

13. Kazantzis G, Hanbury W: Induction of sarcoma in the rat by cadmium sulphide and by cadmium oxide. Ber J Cancer 1966, 20:190-199

14. Stoner G, Shimkin M, Troxell M, Thompson T, Terry L: Test for carcinogenecity of metallic compounds by the pulmonary tumour response in strain A mice. Cancer Res 1976, 36:1744-1747

15. Lemen R, Lee J, Wagoner J, Blejer H: Cancer mortality among cadmium production workers. Ann NY Acad Sci 1976, 271:273279

16. Kolonel L: Association of cadmium with renal cancer. Cancer 1976, 37:1782-1787

17. Kolonel L, Winkelstein W: Cadmium and prostate carcinoma. Lancet 1977, 2:566-567

18. Sunderman F: Metal carcinogenesis. In: Advances in Modern Toxicology (Edited by Goyer R, Mchlman M) 1977, 2:257-295

19. Sunderman F: Carcinogenic effects of metals. Fed Proc 1978, 37:40-46

20. Lauwerys R: Health effects of cadmium. In: Trace Metal Exposure and Health Effects (Edited by DiFerrante E) London, Pergamon Press 1979a43-64

21. Lauwerys R: Cadmium in man. In: The Chemistry, Biochemistry and Biology of Cadmium (Edited by Webb M) Amsterdam, Elsevier 1979b433455

22. Leonard A: Carcinogenic and mutagenic effects of metals (As, $\mathrm{Cd}, \mathrm{Cr}, \mathrm{Hg}, \mathrm{Ni}$ ), present state of knowledge and needs for further studies. In: Trace Metals Exposure and Health Effects (Edited by DiFerrante) London, Pergamon Press 1979199-216

23. Heddle J, Bruce W: On the use of multiple assay for mutagenecity, especially the micronuclei, Salmonella and sperm abnormality assays. In: Progress in Genetics and Toxicology (Edited by Scott D, Bridges B, Sobels F) 1977265-274

24. Bruce $W$, Heddle J: The mutagenic activity of $6 \mathrm{I}$ agents as determined by the micronucleus, Salmonella and sperm abnormality assay. Can J Genet Cytol I 979, 2 I:3 I 9-334

25. Kalinina L, Polukhina G, Lukasheva L: Salmonella typhimurium test system for indication of mutagenic activity of environmental hazards, I. Detection of mutagenic effect of heavy metal salts using in vivo and in vitro assays without metabolic activation. Genetika 1977, 13:1089-1092

26. Deknudt G: Mutagenecity of heavy metals. Mutat Res 1978, 53:176

27. Deknudt G, Gerber G: Chromosomal aberrations in bone marrow cells of mice given a normal or a calcium deficient diet supplemented with various heavy metals. Mutat Res 1979, 68:163-168

28. Degreave N: Contribution a petude des mechanisms d'action des agents d'alkylation, Modification des effects du methane sulfonate d'ethyl sur les chromosomes de l'orge. Doctoral Thesis (Univ Leage) 1969

29. Mukheriee A, Sharma A, Talukdar B: Effect of selenium on cadmium induced chromosomal aberrations in bone marrow cells of mice. Toxicol Lett 1988, 41:23-29

30. Mitra K, Kundu SN, Khuda-Bukhsh AR: Efficacy of a potentized homoeopathic drug (Arsenicum Album-30) in reducing toxic effects produced by arsenic trioxide in mice: I. On rate of accumulation of arsenic in certain vital organs. Complementary Therapies in Medicine 1998, 6:178-184

3I. Mitra K, Kundu SN, Khuda-Bukhsh AR: Efficacy of a potentized homoeopathic drug (Arsenicum Album-30) in reducing toxic effects produced by arsenic trioxide in mice: II. On alterations of body weight, tissue weight and total protein. Complementary Therapies in Medicine 1999, 7:24-34

32. Datta S, Mallick P, Khuda-Bukhsh AR: Efficacy of a potentized homeopathic drug (Arsenicum Album-30) in reducing genotoxic effects produced by arsenic trioxide in mice: $I$. Comparative studies of pre-, post- and combined pre- and post-oral administration and comparative efficacy of two microdoses. Complementary Therapies in Medicine 1999a, 7:62-75

33. Datta S, Mallick P, Khuda-Bukhsh AR: Efficacy of a potentized homeopathic drug (Arsenicum Album-30) in reducing genotoxic effects produced by arsenic trioxide in mice: II. Comparative efficacy of an antibiotic, actinomycin $D$ alone and in combination with either of two microdoses. Complementary Therapies in Medicine 1999b, 7:156-163

34. Kundu SN, Mitra K, Khuda-Bukhsh AR: Efficacy of a potentized homoeopathic drug (Arsenicum Album-30) in reducing cytotoxic effects produced by arsenic trioxide in mice: III. Enzymatic changes and recovery of tissue damage in liver. Complementary Therapies in Medicine 2000a, 8:76-8I

35. Kundu SN, Mitra K, Khuda-Bukhsh AR: Efficacy of a potentized homoeopathic drug (Arsenicum Album-30) in reducing cytotoxic effects produced by arsenic trioxide in mice: IV. Pathological changes, protein profiles and content of DNA and RNA. Complementary Therapies in Medicine 2000b, 8:157-175

36. Crippa $M$ : The mouse karyotype in somatic cells cultured in vitro. Chromosoma 1964, I5:30I-3II

37. Khuda-Bukhsh AR, Maity S: Alterations of cytogenetic effects by oral administrations of a homoeopathic drug, Ruta Graveolens, in mice exposed to sub-lethal $\mathbf{X}$-irradiation. Ber J Res Hom I99|, I:264-274

38. Banik S, Khuda-Bukhsh AR: Alterations of cytogenetical and haematological effects by ultra-low doses of Ginseng in whole-body X-irradiated mice. The Nucleus 1996, 49:28-35

39. Khuda-Bukhsh AR, Banik S: Quantitative assessment of sperm head anomaly in $\mathrm{X}$-irradiated mice and the alteration of frequency by the oral administration of a potentized homoeopathic drug, Ginseng. Proceedings of a Symposium Zoological research in relation to man and environment, Calcutta University, I-4 March 1992. In: Proc. Zoological Society, Calcutta 1992, 45:243-248

40. Fisher RA, Yates F: Statistical Tables for Biological, Agricultural and Medical Research. 4th edn, Oliver \& Boyd, Edinburgh 1953

41. Boiron J, Abecassis J, Belon P: Aspects of Research in Homeopathy 1983, I:19-37

42. Cazin JC, Cazin M, Gaborit JL, Chaoui A, Boiron J, Belon P, Cherruault $Y$, Papapanayotou C: $A$ study of the effect of decimal and centicemal dilutions of arsenic on the retetion and mobilization of arsenic in the rat. Human Toxicol, 1987, 6.315-320

43. Miyake M, Murata I, Osabe M, Ono T: Effect of metal cations on misincorporation by E. coli DNA polymerase. Biochem Biophys Res Commun 1979, 77:854-860

44. Popenoe E, Schmaeler M: Interaction of human DNA polymerase $\beta$ with ions of copper and lead and cadmium. Arch Biochem Biophys 1979, 196:109-120

45. Mitra R, Bernstein I: Nature of the repair process associated with the recovery of $E$. coli DNA polymerase after exposure to Cd++. Biochem Biophys Res Commun 1977, 74: / 450-1455

46. Privezentsev KV, Sirota NP, Gaziev Al: The genotoxic effects of cadmium studied in vivo. Tsitol Genet |996, 30:45-5 |

47. Cooper GM: The Cell - A Molecular Approach. ASM Press, Washington D C 1997

48. Lewin B: Genes VI. Oxford University Press, New York 1997

49. Gardner EJ, Snaustad DP: Principles of Genetics. 7th ed, John Wiley and Sons, New York 1984

50. Khuda-Bukhsh AR: Potentized homoeopathic drugs act through regulation of gene-expression: a hypothesis to explain their mechanism and pathways of action in vivo. Complementary Therapies in Medicine 1997, 5:43-46 